\title{
FAKTOR- FAKTOR YANG BERHUBUNGAN DENGAN PENGGUNAAN POCKET DOSEMETER PADA PETUGAS RADIOLOGI DI INSTALASI RADIOLOGI 9 RUMAH SAKIT B ANDAR LAMPUNG
}

\author{
Leny Anggraeni \\ AKTEK Radiodiagnostik dan Radioterapi Patriot Bangsa, Lampung \\ Email:leny_rad@yahoo.co.id
}

\begin{abstract}
ABSTRAK
Peralatan proteksi radiasi Thermoluminisence Dosemeter (TLD) Badge dapat mengurangi dan melindungi Petugas Radiologi. Tujuan penelitian untuk mengetahui faktor yang berhubungan terhadap penggunaan pocket dosemeter dalam kaitan bahaya radiasi terhadap kesehatan dan keselamatan petugas dengan tingkat paparan yang berbeda. Desain Penelitian Kuantitatif dengan pendekatan crossectional, Jumlah responden 59 orang. Data primer berupa angket, kuesioner penelitian terdiri dari karakteristik responden, tingkat pengetahuan, sikap, ketersediaan alat, kenyamanan, pelatihan, dan pengawasan. Analisis data menggunakan analisis univariat yang divisualisasikan dalam bentuk tabel. Analisa ini dilakukan dengan menghitung distribusi dan prosentase dari tiap variable, sedangkan Analisis bivariat menggunakan uji chi square dan Analisis multivariat dengan menggunakan regresi logistik. Hasil penelitian menunjukkan variabel pengetahuan nilai $p$ value $=, 018$. Sikap nilai $p$ value $=, 038$. Ketersediaan alat nilai $p$ value $=, 004$. Kenyamanan nilai $p$ value $=, 010$. Pelatihan nilai $p$ value $=, 021$. Pengawasan nilai $p$ value $=, 003$. Analisis multivariat didapat nilai $p$ value $=, 003$ variabel pengawasan merupakan variabel yang paling dominan berhubungan dengan penggunaan pocket dosemeter. Hasil penelitian didapat adanya kesesuaian izin operasional alat, ketersediaan petugas PPR, adanya monitoring pemantauan dosis radiasi, penyelenggaraan pemeriksaan kesehatan petugas, ketersediaan standar operasional prosedur dan ketersediaan peralatan keselamatan radiasi yang memadai di lingkungan kerja.
\end{abstract}

Kata kunci: Alat Pelindung Diri, Pocket dosemeter, TLD

\begin{abstract}
Radiation protection equipment Thermoluminisence Dosemeter (TLD) Badge can reduce and protect Radiology Officers. The purpose of this study was to determine the factors associated with the use of pocket dosemeter in the danger of radiation to the health and safety of officers with different levels of ease. Quantitative Research Design with Crossectional, the number of respondents 59 people. Primary data consisted of questionnaires, research questionnaires consisting of the characteristics of respondents, level of knowledge, attitude, approval of tools, comfort, training, supervision. Data analysis uses Univariate analysis which is visualized in tabular form. This analysis is done by calculating the distribution and percentage of each variable, while the bivariate analysis uses the chi square test and multivariate
\end{abstract}


analysis using logistic regression. The results showed the knowledge variable $p$ value $=0$, 018. Attitude $p$ value $=0,038$. The value of the tool $p$ value $=0,004$. The value of $p$ value $=010$. Training the value of $p$ value $=, 021$. Monitoring the value of $p$ value $=, 003$. Multivariate analysis obtained $p$ value $=.003$, the control variable is the most dominant variable related to the use of pocket dosemeter. The results of the study were obtained from the appropriateness of the operational permit for the equipment, the approval of the PPR officer, there was monitoring of the radiation allocation, the organization of the health check of the officers, according to standard operating procedures and adequate radiation safety equipment in the work environment.

Keywords: Personal Protective Equipment, Pocket dosemeter, TLD

\section{PENDAHULUAN}

Perkembangan ilmu pengetahuan dan teknologi dewasa ini semakin maju salah satu upaya meningkatkan kesejahteraan manusia harus dilakukan melalui pekerjaan yang selaras dengan lingkungan kerja yang aman, nyaman dan higienis, sehingga produktifitas, kesehatan dan keselamatan kerja tenaga kerja senantiasa terjamin. Pemeriksaan diagnostik radiologi telah menjadi bagian yang tidak dapat dipisahkan dari kehidupan kita sehari-hari, terutama didalam penatalaksanaan klinis pasien di dalam pelayanan kesehatan. Pemanfaatan radiasi dalam bidang kesehatan terus mengalami peningkatan dari waktu ke waktu, pemanfaatan radiasi ini meliputi tindakan radiodiagnostik, radioterapi dan kedokteran nuklir, ketiga bidang ini disamping memberikan manfaat yang besar, dapat pula memberikan ancaman bahaya radiasi yang perlu diwaspadai. Faktor keselamatan adalah tujuan utama, semua tindakan pemanfaatan radiasi baik untuk diagnostik, terapi maupun kedokteran nuklir harus selalu melalui proses Justifikasi, Limitasi dan Optimasi. Pemanfaatan radiasi akan lebih baik jika kerugian yang ditimbulkan dapat ditekan serendah mungkin atau dihilangkan sama sekali baik terhadap pasien, petugas dan lingkungan yang berada disekitarnya (Akhadi, 2000).

Penggunaan Alat Pelindung Diri (APD) atau peralatan proteksi radiasi dan personal monitor radiasi Thermoluminisence Dosemeter (TLD) Badge dapat mengurangi dan melindungi Petugas Radiologi (radiografer) sebagai pekerja radiasi di rumah sakit dari bahaya kesehatan baik efek genetik, efek stokastik maupun non stokastik. Berdasarkan Undang-undang No.13 Tahun 2003 pasal 87 tentang keselamatan dan kesehatan kerja, Setiap perusahaan wajib menerapkan sistem manajemen keselamatan dan kesehatan kerja yang terintegrasi dengan sistem manajemen perusahaan. Jika memperhatikan isi dari pasal tersebut maka jelaslah bahwa Rumah Sakit termasuk dalam kriteria tempat kerja dengan berbagai ancaman bahaya yang dapat menimbulkan dampak kesehatan, tidak hanya terhadap pelaku langsung yang bekerja di Rumah Sakit tapi juga terhadap pasien maupun penunjang Rumah sakit, sudah seharusnya pihak pengelola Rumah sakit menerapkan upaya kesehatan kerja di Rumah sakit.

Pelayanan radiologi harus memperhatikan aspek Keselamatan dan Kesehatan Kerja (K3) dalam pemanfaatan pelayanan yang menggunakan medan radiasi pengion melalui tindakan proteksi radiasi, baik berupa kegiatan survey radiasi, personal monitoring, jaminan kualitas radiodiagnostik, ketaatan terhadap prosedur kerja, standar pelayanan radiografi, standar prosedur pemeriksaan radiografi semua perangkat tersebut untuk meminimalkan tingkat paparan radiasi yang diterima oleh pekerja radiasi, pasien maupun lingkungan dimana pesawat radiasi pengion dioperasikan. Untuk melindungi petugas radiologi dari paparan radiasi pengion yang berbahaya, pemerintah telah mengatur melalui Pasal 20 UU No 10 Tahun 1997 dan Peraturan Pemerintah RI No. 63 Tahun 2000 Tentang Ketenaganukliran, dipandang perlu ditetapkan peraturan pemerintah tentang Keselamatan dan Kesehatan Terhadap Pemanfaatan Radiasi Pengio n sebagai penyempurnaaan dari 
UU No 31 Tahun 1964 tentang Ketentuan Pokok Tenaga Atom dimaksudkan agar dapat mengikuti perkembangan pemanfaatan tenaga nuklir di Indonesia diberbagai bidang sehingga dalam pemanfaatannya dapat menjamin keselamatan pekerja, masyarakat maupun lingkungan hidup. Salah satu potensi bahaya yang dapat ditimbulkan oleh pemanfaatan radiasi pengion adalah timbulnya efek radiasi baik yang bersifat non stokastik, stokastik dan efek genetik yang mungkin timbul akibat pekerja radiasi mendapat paparan radiasi. Efek tersebut dapat berupa Radiation Sicknes, penyakit keganasan sampai timbul penyakit yang timbul pada keturunannya (akibat timbulnya efek genetik) yang disebabkan adanya penerimaan paparan radiasi eksterna dalam jumlah kecil namun diterima dalam jangka waktu yang lama (Batan, 2008).

Berdasarkan Laporan Keselamatan Nuklir pada tahun 2009 Bapeten telah melaksanakan inspeksi sebanyak 54 keberangkatan dengan cakupan 16 provinsi, dengan fasilitas yang diinspeksi berjumlah 475 fasilitas dengan rincian 362 fasilitas kesehatan, dan 113 fasilitas industri dan penelitian. Jumlah, frekuensi, wilayah dan fasilitas yang di inspeksi ini ditentukan berdasarkan parameter tingkat resiko dan ketersediaan sumber daya manusia. Hasil inspeksi yang dilaksanakan pada fasilitas radiologi diagnostik dan intervensional menunjukkan bahwa 954 pesawat sinar- $\mathrm{x}$ telah memiliki izin dan 254 pesawat sinar-x belum memiliki izin pemanfaatan. Pemeriksaan kondisi fasilitas juga mencakup kondisi ruangan, peralatan pemantauan dosis perorangan Thermoluminisence Dosemeter (TLD) Badge, baju apron, ruang operator dan ketersediaan tabir dan tanda bahaya radiasi lainnya, dari hasil inspeksi ditemukan 97\% atau 351 instansi telah memiliki Thermoluminisence Dosemeter (TLD) Badge/Apron, 97,5\% atau 353 instansi telah memiliki ruang operator/tabir dan 73,7\% atau 267 instansi telah menyediakan lampu/tanda peringatan bahaya radiasi.

Berdasarkan hasil inspeksi data diatas, dapat disimpulkan bahwa sebanyak $65,5 \%$ atau 237 fasilitas kesehatan dalam kondisi baik dan memenuhi seluruh persyaratan keselamatan yang telah ditetapkan dalam perundang-undangan, 29\% atau 105 instansi dalam kondisi cukup baik, memenuhi sebagian besar persyaratan keselamatan kecuali tanda/tulisan/lampu tanda radiasi dan sisanya 5,5\% atau 20 fasilitas kesehatan dalam kondisi kurang atau belum memenuhi persyaratan keselamatan. Terhadap ke 20 instansi tersebut Badan Pengawas Tenaga Atom (BAPETEN) telah memberikan sanksi berupa peringatan tegas secara tertulis, ancaman pencabutan izin dan perintah untuk segera melengkapi/memenuhi kekurangan dalam memenuhi salah satu persyaratan keselamatan. Berdasarkan Laporan Keselamatan Nuklir pada tahun 2015 Bapeten telah melaksanakan Inspeksi Fasilitas Radiasi dan Zat Radioaktif (FRZR) di 17 provinsi, dengan Instansi yang diinspeksi berjumlah 512 Instansi dengan rincian 375 Instansi kesehatan, dan 137 Instansi Industri dan Penelitian. Menunjukkan bahwa secara umum objek pengawasan instalasi dan bahan nuklir dioperasikan secara selamat dan aman dengan catatan masih perlu peningkatan budaya keselamatan dan keamanan secara memadai untuk meningkatkan performa keselamatan dan keamanan secara berkelanjutan.

Selanjutnya secara garis besar hasil inspeksi keselamatan pemanfaatan tenaga nuklir pada fasilitas kesehatan yang meliputi radiologi diagnostik dan interventional serta radioterapi dan kedokteran nuklir menunjukkan masih perlunya kesadaran dan ketaatan pemegang izin dalam melaksanakan pemanfaatan tenaga nuklir dengan berbasis pada budaya Keselamatan dan kesehatan Kerja sedangkan hasil serupa juga tidak jauh berbeda terhadap keselamatan pada fasilitas dan industri yang terdiri dari fasilitas radiografi industri, well logging, gauging, foto fluoroscopy bagasi, analisa, iradiator dan akselerator (BAPETEN, 2012).

Pada tahun 2015 BAPETEN, telah melakukan kordinasi penegakan hukum di empat wilayah hukum provinsi, yaitu Kalimantan Timur, Sumatera Selatan, Jawa Barat, dan Jawa Tengah. Mekanisme penegakan hukum atau pemberian sanksi terhadap pelanggaran pemanfaatan tenaga nuklir sebagaimana telah diatur dalam Undang - undang Nomor 10 tahun 1997, Peraturan 
Pemerintah Nomor 33 Tahun 2007 dan Peraturan Pemerintah No mor 29 Tahun 2008. Upaya yang telah dilakukan BAPETEN dalam rangka pelaksanaan penegakan hukum ketenaganukliran meliputi yaitu, Tindakan Preventif (Pencegahan), Tindakan Persuasif (pembinaan), dan Tindakan Penegakan hukum secara Represif. Selain melakukan koordinasi, BAPETEN juga telah melakukan tindakan penegakan hukum terhadap 14 Instansi terdiri dari 9 Instansi kesehatan dan 5 Instansi Industri. Instansi yang dilakukan penegakan hukum berada di daerah hukum Polda Sumatra Utara (2 kasus), Polda Jawa Barat (2 Kasus), Polda Jawa Timur (7 kasus), Polda Kepulauan Riau (1 kasus), dan Polda Metro Jaya (2 kasus). Keberhasilan tindakan penegakan hukum ini diukur dengan jumlah instansi yang diproses sampai ke pengadilan dibandingkan dengan jumlah instansi yang sudah dilaporkan. Realisasi persentase jumlah pelaporan penegakan hukum yang ditindaklanjuti sampai ke pengadilan sebesar 64,3\% atau lebih besar dari target (60\%).

Berdasarkan peraturan Badan Pengawas Tenaga Nuklir (BAPETEN) Nomor 3 Tahun 2013, Keselamatan Radiasi adalah Tindakan yang dilakukan untuk melindugi pasien, pekerja, anggota masyarakat dan lingkungan hidup dari bahaya radiasi. Proteksi radiasi yang dilakukan untuk mengurangi pengaruh radiasi yang merusak akibat paparan radiasi, menjadi suatu keharusan untuk mewujudkan keselamatan radiasi. Nilai Batas Dosis (NBD) untuk pekerja radiasi tidak boleh melampaui $20 \mathrm{mSv}$ (millisievert) per tahun rata-rata selama 5 tahun berturut- turut dan $50 \mathrm{mSv}$ dalam 1 tahun tertentu, sedangkan NBD untuk anggota masyarakat tidak boleh melampaui $1 \mathrm{mSv}$ dalam 1 tahun. Pemantauan dosis radiasi yang diterima oleh pekerja radiasi dilakukan dengan menggunakan film badge atau Thermoluminisence Dosemeter (TLD) badge, dan dosimeter pembacaan langsung yang terkalibrasi.

Aspek keselamatan radiologis mendapatkan prioritas tinggi dalam pemanfaatan dibidang radiologi karena pada prinsipnya pemaparan radiasi yang tidak dikehendaki terhadap tubuh manusia akan memberikan efek negatif terhadap kesehatan. Salah satu persyaratan standar keamanan adalah ketebalan dinding ruangan sehingga kebocoran radiasi dari dalam fasilitas itu tidak melampaui nilai batas yang telah ditentukan, dalam hal ini dinding ruangan akan berperan sebagai perisai radiasi. Penerimaan dosis paparan radiasi eksterna pada pekerja di medan radiasi harus dimonitoring untuk menentukan jumlah radiasi yang diterima seseorang dan selanjutnya diusahakan agar jumlah radiasi yang diterima tidak melebihi dari Nilai Batas Dosis (NBD) yang telah ditentukan. Berdasarkan profil dinas kesehatan Tahun 2014, Provinsi lampung memiliki beberapa sarana pelayanan kesehatan rujukan masyarakat sebanyak 58 RS Pemerintah, Swasta, Umum dan Khusus) yang terdiri atas 14 RSUD, 1 RS Jiwa, 1 RS DKT, 1 RS Bhayangkara Polri, 30 RSU Swasta dan 12 RS Khusus yang semua nya telah memiliki pelayanan laboratorium sebagai penunjang diagnosa salah satunya yaitu instalasi radiologi yang kegiatannya berkaitan dengan sumber paparan radiasi pada pekerja ataupun lingkungannya.

Untuk menjamin paparan radiasinya aman bagi pekerja, maka perlu dilakukan penelitian tentang paparan radiasi pada para pekerja tersebut, oleh karena itu diperlukan suatu studi terhadap penerimaan dosis pekerja radiasi untuk menunjukkan dipenuhi atau tidaknya system pembatasan dosis yang direkomendasikan oleh International Commisision On Radiological Protection (ICRP) tahun 1990 maupun Badan Pengawas Tenaga Nuklir (Bappeten) tahun 2013. Dalam hal ini salah satunya adalah pekerja radiasi yang berada di Instalasi Radiologi Rumah Sakit Kota Bandar Lampung, mengingat merupakan pekerja/tenaga kesehatan yang selalu berada didalam medan radiasi pengion, karena selalu bekerja dengan pesawat sinar-X yang merupakan salah satu sumber radiasi pengion.

Hasil pra survey yang peneliti lakukan melalui observasi di instalasi radiologi pada 9 Rumah Sakit di Kota Bandar Lampung, masih terdapat petugas yang belum disiplin memakai APD dalam melaksanakan pemeriksaan radiologi padahal banyak potensi bahaya radiasi yang dapat mengancam petugas radiologi (radiografer) dalam bekerja. Data yang diperoleh dari Balai 
Pengamanan Fasilitas Kesehatan (BPFK) Departemen Kesehatan RI da n Badan Tenaga Nuklir Nasional Laporan Hasil Pemantauan Dosis Radiasi Perorangan Pada Tahun 2014-2016, dari 72 orang tenaga kesehatan radiologi ditemukan ada beberapa orang pekerja yang mendapatkan dosis paparan radiasi yang cenderung naik melebihi batas dosis yang diperkenankan. Dengan demikian pekerja/tenaga kesehatan di Instalasi Radiologi Rumah Sakit Kota Bandar Lampung mempunyai resiko terkena paparan radiasi selama melaksanakan tugasnya sebagai penyelenggara pelayanan kesehatan bidang radiologi, sehingga kemungkinan besar akan berpotensi mengalami efek akibat pemanfaatan radiasi sinar-X.

Berdasarkan data diatas, peneliti tertarik untuk melakukan penelitian tentang ; " Faktor-Faktor yang berhubungan dengan Penggunaan Pocket Dosimeter Pada Petugas Radiologi Di Instalasi Radiologi pada 9 Rumah Sakit di Kota Bandar Lampung". Alat pelindung diri (APD) adalah kelengkapan yang wajib digunakan saat bekerja sesuai bahaya dan resiko kerja untuk menjaga keselamatan pekerja itu sendiri dan orang disekitarnya. Keselamatan Radiasi adalah upaya yang dilakukan untuk menciptakan kondisi yang sedemikian rupa agar efek radiasi pengion terhadap manusia dan lingkungan hidup tidak melampaui nilai batas yang ditentukan.

Jaminan Kualitas Radiologi (Radilogic Quality Assurance) didefinisikan sebagai kegiatan dari seluruh staf yang mengoperasikan fasilitas dan peralatan radiodiagnostik yang mempunyai mental dasar untuk berfikir dan bertindak serta sadar akan pentingnya kualitas. Dengan demikian akan selalu terjamin baik fisik maupun fungsi semua fasilitas dan peralatan radiodiagnostik dapat layak pakai. Tidak akan terjadi lagi kesalahan-kesalahan pengoperasian alat, teknik pemeriksaan maupun keslahan yang diakibatkan oleh kelalaian radiografer dan pekerja lainnya, karena selalu taat terhadap standar prosur kerja yang telah ditetapkan.

Keselamatan Kerja dalam Radiologi mempunyai risiko baik secara langsung maupun tidak langsung, risiko tersebut dapat terjadi bila kelalaian dan sebab-sebab lain di luar kemampuan manusia. Menjadi tanggung jawab bagi manusia untuk mempelajari kemungkinan adanya bahaya dalam pekerjaan agar mampu mengendalikan bahaya serta mengurangi risiko sekecil-sekecilnya melalui pemahaman mengenai berbagai aspek bahaya dalam lingkungan radiologi, mengarahkan para pekerja dalam melaksanakan keselamatan dan kesehatan kerja (Imamkhasani, 1990).

\section{METODOLOGI PENELITIAN}

Desain penelitian yang digunakan adalah cross sectional dengan jumlah 59 responden, lokasi penelitian di di instalasi Radiologi pada 9 Rumah Sakit Bandar Lampung. Pengambilan data primer berupa angket yang berisi tentang pengetahuan, sikap, ketersediaan alat, kenyamanan, pelatihan dan pengawasan dengan Teknik pengambilan sampel menggunakan accidental sampling dikarenakan ada pembagian jadwal shift dari petugas radiasi selama penelitian dilakukan.

\section{HASIL DAN PEMBAHASAN}

Tabel 1. Distribusi frekuensi faktor-faktor yang berhubungan dengan penggunaan pocket dosemeter pada petugas radiologi

\begin{tabular}{|c|c|c|c|}
\hline & Variabel & Frekuensi & Persentase \% \\
\hline \multicolumn{4}{|c|}{ Pengetahuan } \\
\hline 1. & Tidak Baik & 10 & 16,9 \\
\hline 2. & Baik & 49 & 83,1 \\
\hline Jumlah & & 59 & $100 \%$ \\
\hline
\end{tabular}




\begin{tabular}{|c|c|c|c|}
\hline \multicolumn{4}{|l|}{ Sikap } \\
\hline 1. & Tidak Baik & 11 & 18,6 \\
\hline 2. & Baik & 48 & 81,4 \\
\hline Jumlah & & 59 & $100 \%$ \\
\hline \multicolumn{4}{|c|}{ Ketersediaan Alat } \\
\hline 1. & Tidak Ada & 11 & 18,6 \\
\hline 2. & Ada & 48 & 81,4 \\
\hline Jumlah & & 59 & $100 \%$ \\
\hline \multicolumn{4}{|c|}{ Kenyamanan } \\
\hline 1. & Tidak & 12 & 20,3 \\
\hline & Nyaman & 47 & 79,7 \\
\hline 2. & Nyaman & & \\
\hline Jumlah & & 59 & $100 \%$ \\
\hline \multicolumn{4}{|c|}{ Pelatihan } \\
\hline & Tidak Ada & 30 & 50,8 \\
\hline 2. & Ada & 29 & 49,2 \\
\hline Jumlah & & 59 & $100 \%$ \\
\hline \multicolumn{4}{|c|}{ Pengawasan } \\
\hline 1. & Tidak Ada & 19 & 32,2 \\
\hline 2. & Ada & 40 & 67,8 \\
\hline Jumlah & & 59 & $100 \%$ \\
\hline \multicolumn{4}{|c|}{$\begin{array}{l}\text { Ketersediaan Fasilitas } \\
\text { Kesehatan }\end{array}$} \\
\hline 1. & Tersedia & 45 & 45 \\
\hline 2. & Tidak & 55 & 55 \\
\hline & Tersedia & & \\
\hline Jumlah & & 100 & $100 \%$ \\
\hline
\end{tabular}

Berdasarkan tabel 1. diatas didapat informasi bahwa distribusi frekuensi tingkat pengetahuan diketahui sebanyak 59 responden, berpengetahuan tidak baik 10 responden (16,9\%), dan pengetahuan baik 49 responden $(83,1 \%)$. Distribusi frekuensi sikap diketahui sebanyak 59 responden, responden memiliki sikap tidak baik 11 responden $(18,6 \%)$ dan sikap baik 48 responden $(81,4 \%)$. Distribusi frekuensi ketersediaan alat diketahui sebanyak 59 responden, sebanyak tidak ada 11 responden $(18,6 \%)$ menyatakan tidak ada dan responden menyatakan ada sebanyak 48 responden $(81,4 \%)$. Distribusi frekuensi kenyamanan diketahui sebanyak 59 responden, tidak nyaman 12 responden $(20,3 \%)$ dan nyaman 47 responden $(79,7 \%)$. Distribusi frekuensi pelatihan diketahui sebanyak 59 responden, tidak ada 30 responden $(50,8 \%)$ dan Ada 29 responden $(49,2 \%)$. Distribusi frekuensi pengawasan diketahui 59 responden, tidak ada 19 responden $(32,2 \%)$ dan Ada 40 responden $(67,8 \%)$.

Tabel 2. Hasil Analisis Bivariat hubungan Tingkat pengetahuan, sikap, ketersediaan alat, kenyamanan, pelatihan, pengawasa dengan penggunaan Pocket Desemeter pada petugas

\begin{tabular}{|c|c|c|c|c|c|c|c|c|c|}
\hline \multirow{3}{*}{\multicolumn{2}{|c|}{ Variabel }} & \multicolumn{4}{|c|}{$\begin{array}{l}\text { Penggunaan pocket } \\
\text { dosemeter }\end{array}$} & \multirow[t]{3}{*}{ n } & \multirow[t]{3}{*}{$\%$} & \multirow[t]{3}{*}{$\begin{array}{c}\mathbf{p} \\
\text { value }\end{array}$} & \multirow[t]{3}{*}{$\begin{array}{c}\text { OR } \\
\text { CI } 95 \%\end{array}$} \\
\hline & & \multicolumn{2}{|c|}{ Tidak Patuh } & \multicolumn{2}{|c|}{ Patuh } & & & & \\
\hline & & $\mathbf{n}$ & $\%$ & n & $\%$ & & & & \\
\hline \multirow{3}{*}{ Pengetahuan } & Tidak baik & 6 & 60,0 & 4 & 40,0 & 10 & 100 & \multirow[t]{3}{*}{.018} & \multirow{3}{*}{$\begin{array}{c}6,667 \\
(1,553- \\
28,627)\end{array}$} \\
\hline & Baik & 9 & 18,4 & 40 & 81,6 & 49 & 100 & & \\
\hline & $\mathrm{n}$ & 15 & 25,4 & 44 & 74,6 & 59 & 100 & & \\
\hline \multirow{2}{*}{ Sikap } & Tidak baik & 6 & 54,5 & 5 & 45,5 & 11 & 100 & \multirow[t]{2}{*}{, 038} & \multirow{2}{*}{$\begin{array}{l}5.200 \\
(1,294 \\
20.890)\end{array}$} \\
\hline & Baik & 9 & 18,8 & 39 & 81,2 & 48 & 100 & & \\
\hline
\end{tabular}




\begin{tabular}{|c|c|c|c|c|c|c|c|c|c|}
\hline & $\mathrm{n}$ & 15 & 25,4 & 44 & 74,6 & 59 & 100 & & \\
\hline \multirow{3}{*}{$\begin{array}{c}\text { Ketersediaan } \\
\text { Alat }\end{array}$} & Tidak baik & 7 & 63,6 & 4 & 36,4 & 11 & 100 & \multirow[t]{3}{*}{,004 } & \multirow{3}{*}{$\begin{array}{ll}8.750 & 9 \\
(2.065- & \\
37.082) & \end{array}$} \\
\hline & Baik & 8 & 16,7 & 40 & 83,3 & 48 & 100 & & \\
\hline & $\mathrm{n}$ & 15 & 25,4 & 44 & 74,6 & 59 & 100 & & \\
\hline \multirow{3}{*}{ Kenyamanan } & Tidak baik & 7 & 58,3 & 5 & & 12 & 100 & \multirow[t]{3}{*}{,010 } & \multirow{3}{*}{$\begin{array}{c}6.825 \\
(1.722- \\
27.044)\end{array}$} \\
\hline & Baik & 8 & 17,0 & 39 & 83,0 & 47 & 100 & & \\
\hline & $\mathrm{n}$ & 15 & 25,4 & 44 & 74,6 & 59 & 100 & & \\
\hline \multirow[t]{3}{*}{ Pelatihan } & Tidak baik & 12 & 40,0 & 18 & 60,0 & 30 & 100 & \multirow[t]{3}{*}{,021 } & \multirow{3}{*}{$\begin{array}{c}5.778 \\
(1.424- \\
23.445)\end{array}$} \\
\hline & Baik & 3 & 10,3 & 26 & 89,7 & 29 & 100 & & \\
\hline & $\mathrm{n}$ & 15 & 25,4 & 44 & 74,6 & 59 & 100 & & \\
\hline \multirow{3}{*}{ Pengawasan } & Tidak baik & 10 & 52,6 & 9 & 47,4 & 19 & 100 & \multirow[t]{3}{*}{,003 } & \multirow{3}{*}{$\begin{array}{c}7.778 \\
(2.120- \\
28.528)\end{array}$} \\
\hline & Baik & 5 & 12,5 & 35 & 87,5 & 40 & 100 & & \\
\hline & $\mathbf{N}$ & 15 & 25,4 & 44 & 74,6 & 59 & 100 & & \\
\hline
\end{tabular}

Berdasarkan tabel 2. diatas dapat diketahui hasil analis pengetahuan yang tidak baik dengan penggunaan pocket dosemeter diperoleh bahwa dari 59 responden yang memiliki pengetahuan tidak baik pada penggunaan pocket yang tidak patuh sebanyak 6 orang $(60,0 \%)$ dan penggunaan pocket yang patuh sebanyak 4 responden $(40,0 \%)$. Sedangkan pada 59 orang responden yang memiliki pengetahuan baik pada penggunaan pocket yang tidak patuh sebanyak 9 responden $(18,4 \%)$ dan yang patuh sebanyak 40 responden $(81,6 \%)$. Hasil Uji Statistik Chi Square diperoleh nilai $p$ value $=, 018$ maka dapat disimpulkan ada hubungan antara pengetahuan dengan penggunaan pocket dosemeter.

Diketahui hasil analisis bahwa dari 59 responden yang memiliki sikap tidak baik pada penggunaan pocket yang tidak patuh sebanyak 6 orang $(54,5 \%)$ dan patuh sebanyak 5 responden $(45,5 \%)$. Sedangkan pada 59 orang responden yang memiliki sikap baik pada penggunaan pocket yang tidak patuh sebanyak 9 responden $(18,8 \%)$ dan penggunaan pocket yang patuh sebanyak 39 responden $(81,2 \%)$. Hasil Uji Statistik Chi Square diperoleh nilai $p$ value $=, 038$ maka dapat disimpulkan ada hubungan antara sikap dengan penggunaan pocket dosemeter.

Diketahui hasil analisis hubungan antara ketersediaan alat dengan penggunaan pocket dosemeter diperoleh bahwa dari 59 responden yang memiliki ketersediaan alat yang tidak ada pada penggunaan pocket yang tidak patuh sebanyak 7 orang $(63,6 \%)$ dan ketersediaan alat yang tidak ada pada penggunaan pocket yang patuh sebanyak 4 responden $(36,4 \%)$. Sedangkan pada 59 orang responden yang memiliki ketersediaan alat yang ada pada penggunaan pocket yang tidak patuh sebanyak 8 responden $(16,7 \%)$ dan ketersediaan alat yang ada pada penggunaan pocket yang patuh sebanyak 40 responden $(83,3 \%)$. Hasil Uji Statistik Chi Square diperoleh nilai $p$ value $=, 004$ maka dapat disimpulkan ada hubungan antara ketersediaan alat dengan penggunaan pocket dosemeter.

Diketahui hasil analisis hubungan antara kenyamanan dengan penggunaan pocket dosemeter diperoleh bahwa dari 59 responden yang tidak nyaman pada penggunaan pocket yang tidak patuh sebanyak 7 orang $(58,3 \%)$ dan yang tidak nyaman pada penggunaan pocket yang patuh sebanyak 5 responden $(41,7 \%)$. Sedangkan pada 59 orang responden yang memiliki kenyamanan dengan penggunaan pocket yang tidak patuh sebanyak 8 responden $(17,0 \%)$ dan kenyamanan pada penggunaan pocket yang patuh sebanyak 39 responden $(83,0 \%)$. Hasil Uji Statistik Chi Square diperoleh nilai $p$ value $=, 010$ maka dapat disimpulkan ada hubungan antara kenyamanan dengan penggunaan pocket dosemeter. 
Diketahui hasil analisis hubungan antara pelatihan dengan penggunaan pocket dosemeter diperoleh bahwa dari 59 responden yang tidak ada pelatiha $n$ pada penggunaan pocket yang tidak patuh sebanyak 12 orang $(40,0 \%)$ dan yang tidak ada pelatihan pada penggunaan pocket yang patuh sebanyak 18 responden $(60,0 \%)$. Sedangkan pada 59 orang responden yang memiliki pelatihan dengan penggunaan pocket yang tidak patuh sebanyak 3 responden $(10,3 \%)$ dan pelatihan pada penggunaan pocket yang patuh sebanyak 26 responden (89,7\%). Hasil Uji Statistik Chi Square diperoleh nilai $p$ value $=, 021$ maka dapat disimpulkan ada hubungan antara pelatihan dengan penggunaan pocket dosemeter. Diketahui hasil analisis hubungan antara pengawasan dengan penggunaan pocket dosemeter diperoleh bahwa dari 59 responden yang tidak ada pengawasan pada penggunaan pocket yang tidak patuh sebanyak 10 orang $(52,6 \%)$ dan yang tidak ada pengawasan pada penggunaan pocket yang patuh sebanyak 9 responden $(47,4 \%)$. Sedangkan pada 59 orang responden yang memiliki pengawasan dengan penggunaan pocket yang tidak patuh sebanyak 5 responden $(12,5 \%)$ dan pengawasan pada penggunaan pocket yang patuh sebanyak 35 responden $(87,5 \%)$. Hasil Uji Statistik Chi Square diperoleh nilai $p$ value $=, 003$ maka dapat disimpulkan ada hubungan antara pengawasan dengan penggunaan pocket dosemeter.

\section{Analisa multivariat}

Analisa multivariat dalam penelitian ini bertujuan untuk mengetahui variabel yang paling dominan antara pengetahuan, sikap, ketersediaan alat, kenyaman, pelatihan dan pengawasan terhadap penggunaan pocket dosemeter personal radiasi pada petugas di instalasi radiologi di Rumah sakit Bandar Lampung.

\section{Seleksi Bivariat}

Sebelum dilakukan analisa multivariat terlebih dahulu dilakukan seleksi kandidat model variabel yang akan diuji dengan regresi logistik berganda dengan pertimbangan wald test ( $p$ value $<0,25)$ maka didapatkan hasil sebagai berikut :

Tabel 3. Seleksi Bivariat

\begin{tabular}{clcc}
\hline No & \multicolumn{1}{c}{ Variabel } & P & OR \\
\hline 1 & Pengetahuan &, 018 & 6,667 \\
\hline 2 & Sikap &, 038 & 5,200 \\
\hline 3 & Ketersediaan Alat &, 004 & 8,750 \\
\hline 4 & Kenyamanan &, 010 & 6,825 \\
\hline 5 & Pelatihan &, 021 & 5,778 \\
\hline 6 & Pengawasan &, 003 & 7,778 \\
\hline
\end{tabular}

Berdasarkan tabel 3 di atas dapat diketahui bahwa variable pengetahuan, sikap, ketersediaan alat, kenyamanan, pelatihan dan pengawasan yang masuk dalam permodelan multivariat karena memiliki nilai $p$ value $<0,25$

2. Permodelan awal analisis multivariate

Setelah dilakukan seleksi model multivariat maka variabel yang masuk dalam permodelan multivariat diuji dengan menggunakan metode regresi logistik ganda, hasil uji ditampilkan dalam tabel sebagai berikut: 
Tabel 4. Model Awal Analisis Regresi Logistik

\begin{tabular}{|c|c|c|c|c|c|c|c|c|}
\hline \multirow{2}{*}{ No } & \multirow{2}{*}{ Variabel } & \multirow{2}{*}{ B } & \multirow{2}{*}{ S.E } & \multirow{2}{*}{ Wald } & \multirow{2}{*}{ Sig } & \multirow{2}{*}{$\begin{array}{l}\operatorname{Exp} \\
(\mathbf{B})\end{array}$} & \multicolumn{2}{|c|}{$95 \% \mathrm{CI}$} \\
\hline & & & & & & & Lower & Upper \\
\hline 1 & Pengetahuan &,- 502 & 1,669 & ,091 &, 763 & 605 & ,023 & 15,938 \\
\hline 2 & Sikap & ,908 & 1,393 & 425 &, 514 & 2,479 &, 162 & 38,005 \\
\hline 3 & $\begin{array}{l}\text { Ketersediaan } \\
\text { Alat }\end{array}$ & ,541 & 1,393 & , 151 & ,698 & 1,718 & , 112 & 26,347 \\
\hline 4 & Kenyamanan &, 744 & 1,541 & ,233 & ,629 & 2,105 & , 103 & 43,141 \\
\hline 5 & Pelatihan & ,815 & ,995 & 671 & ,413 & 2,260 & ,321 & 15,893 \\
\hline 6 & Pengawasan & 1,825 & 1,155 & 2,498 &, 114 & 6,202 & ,645 & 59,623 \\
\hline & Constan & $-12,382$ & 4,359 & 8,068 &, 005 &, 000 & & \\
\hline
\end{tabular}

Berdasarkan tabel 4. di atas dapat diketahui bahwa ada 6 variabel yang mempunyai nilai $p$ value $>0,05$, maka variabel yang memiliki nilai signifikan terbesar yaitu variabel pengetahuan dikeluarkan dari model.

Tabel 5. Hasil analisis Regresi Logistik dengan mengeluarkan variabel Pengetahuan

\begin{tabular}{|c|c|c|c|c|c|c|c|c|}
\hline \multirow{2}{*}{ No } & \multirow{2}{*}{ Variabel } & \multirow{2}{*}{ B } & \multirow{2}{*}{ S.E } & \multirow{2}{*}{ Wald } & \multirow{2}{*}{ Sig } & \multirow{2}{*}{$\begin{array}{c}\text { Exp } \\
\text { (B) }\end{array}$} & \multicolumn{2}{|c|}{$95 \% \mathrm{CI}$} \\
\hline & & & & & & & Lower & Upper \\
\hline 1 & Sikap & 648 & 1,120 & ,334 &, 563 & 1,912 &, 213 & 17,184 \\
\hline 2 & $\begin{array}{l}\text { Ketersediaan } \\
\text { alat }\end{array}$ & ,449 & 1,368 & ,108 & ,743 & 1,566 & ,107 & 22,889 \\
\hline 3 & Kenyamanan & 677 & 1,542 & , 193 & ,661 & 1,967 & ,096 & 40,377 \\
\hline 4 & Pelatihan & ,779 & ,998 &, 610 &, 435 & 2,180 & ,308 & 15,400 \\
\hline 5 & Pengawasan & 1,832 & 1,162 & 2,488 &, 115 & 6,248 & ,641 & 15,400 \\
\hline & Constan & $-12,593$ & 4,381 & 8,262 &, 004 &, 000 & & \\
\hline
\end{tabular}

Berdasarkan tabel 5. di atas dapat diketahui bahwa terdapat 5 variabel yang mempunyai nilai $p$ value $>0,05$, sehingga variabel ketersediaan alat harus dikeluarkan dari model.

Tabel 6. Hasil analisis Regresi Logistik dengan mengeluarkan variabel Ketersediaan Alat

\begin{tabular}{|c|c|c|c|c|c|c|c|c|}
\hline \multirow{2}{*}{ No } & \multirow{2}{*}{ Variabel } & \multirow{2}{*}{ B } & \multirow{2}{*}{ S.E } & \multirow{2}{*}{ Wald } & \multirow{2}{*}{ Sig } & \multirow{2}{*}{$\begin{array}{r}\operatorname{Exp} \\
\text { (B) }\end{array}$} & \multicolumn{2}{|c|}{$95 \% \mathrm{CI}$} \\
\hline & & & & & & & Lower & Upper \\
\hline 1 & Sikap &, 730 & 1,085 & , 452 & ,501 & 2,074 & ,248 & 17,382 \\
\hline 2 & Kenyamanan &, 793 & 1,498 & ,281 & ,596 & 2,211 &, 117 & 41,645 \\
\hline 3 & Pelatihan & ,851 & ,978 & ,758 & ,384 & 2,343 & ,344 & 15,936 \\
\hline \multirow[t]{2}{*}{4} & Pengawasan & 2,010 & 1,018 & 3,901 &, 048 & 7,462 & 1,016 & 54,822 \\
\hline & Constan & $-12,545$ & 4,386 & 8,183 &, 004 &, 000 & & \\
\hline
\end{tabular}

Berdasarkan tabel 6. diatas dapat diketahui bahwa terdapat 3 variabel yang mempunyai nilai $p$ value $>0,05$, sehingga variabel kenyamanan harus dikeluarkan dari model.

Tabel 7. Hasil analisis Regresi Logistik dengan mengeluarkan variabel Kenyamanan

\begin{tabular}{|c|c|c|c|c|c|c|c|c|}
\hline \multirow{2}{*}{ No } & \multirow{2}{*}{ Variabel } & \multirow{2}{*}{ B } & \multirow{2}{*}{ S.E } & \multirow{2}{*}{ Wald } & \multirow{2}{*}{ Sig } & \multirow{2}{*}{$\begin{array}{c}\mathbf{E x p} \\
(\mathbf{B})\end{array}$} & \multicolumn{2}{|c|}{$95 \% \mathrm{CI}$} \\
\hline & & & & & & & Lower & Upper \\
\hline 1 & Sikap &, 748 & 1,071 & ,488 &, 485 & 2,113 & ,259 & 17,253 \\
\hline 2 & Pelatihan &, 653 & ,896 &, 531 &, 466 & 1,921 & ,332 & 11,120 \\
\hline 3 & Pengawasan & 2,246 & ,924 & 5,903 & ,015 & 9,449 & 1,544 & 57,838 \\
\hline
\end{tabular}




\begin{tabular}{llllll}
\hline Constan & $-12,545$ & 4,046 & 8,452 &, 004 &, 000 \\
\hline
\end{tabular}

Berdasarkan tabel 7. diatas dapat diketahui bahwa terdapat 2 variabel yang mempunyai nilai $p$ value $>0,05$, sehingga variabel sikap harus dikeluarkan dari model.

Tabel 8. Hasil analisis Regresi Logistik dengan mengeluarkan variabel Sikap

\begin{tabular}{|c|c|c|c|c|c|c|c|c|}
\hline \multirow{2}{*}{ No } & \multirow{2}{*}{ Variabel } & \multirow{2}{*}{ B } & \multirow{2}{*}{ S.E } & \multirow{2}{*}{ Wald } & \multirow{2}{*}{ Sig } & \multirow{2}{*}{$\begin{array}{c}\operatorname{Exp} \\
\text { (B) }\end{array}$} & \multicolumn{2}{|c|}{$95 \% \mathrm{CI}$} \\
\hline & & & & & & & Lower & Upper \\
\hline 1 & Pelatihan & ,797 & ,871 & ,836 &, 360 & 2,218 & ,402 & 12,237 \\
\hline 2 & Pengawasan & 2,227 & ,906 & 6,038 & ,014 & 9,269 & 1,569 & 54,747 \\
\hline & Constan & $-10,681$ & 3,600 & 8,801 & ,003 & ,000 & & \\
\hline
\end{tabular}

Berdasarkan tabel 8. diatas dapat diketahui bahwa terdapat variabel pelatihan mempunyai nilai $p$ value $>0,05$, sehingga variabel pelatihan harus dikeluarkan dari model dan tersisa satu variabel yang memiliki nilai $p$ value $<0,05$ yaitu variabel pengawasan dan merupakan variabel yang paling dominan berhubungan dengan penggunaan pocket dosemeter personal radiasi.

\section{Pengetahuan}

Hasil distribusi responden berdasarkan pengetahuan pada pengguna pocket dosemeter berpengetahuan tidak baik dan tidak patuh sebesar $60 \%$, sedangkan pengguna pocket dosemeter berpengetahuan baik dan patuh sebesar $81,6 \%$. Hal tersebut dapat terlihat bahwa persentase petugas yang berpengetahuan baik lebih besar dan patuh terhadap penggunaan pocket dosemeter dibandingkan pada kelompok yang berpengetahuan tidak baik. Hasil penelitian sejalan dengan teori yang dikemukakan Notoatmodjo (2010) bahwa secara umum seseorang yang berpendidikan lebih tinggi akan mempunyai pengetahuan yang lebih luas dibandingkan dengan seseorang yang memiliki pendidikan yang lebih rendah.

Menurut Notoatmodjo (2012), Pendidikan merupakan salah satu faktor pada karakteristik tenaga kerja yang akan mempengaruhi perilaku. Pendidikan juga akan mempengaruhi tenaga kerja dalam upaya pencegahan penyakit dan meningkatkan kemampuan memelihara kesehatan. Meskipun pendidikan memiliki kuat hubungan yang rendah dengan kepatuhan menggunakan APD namun pendidikan tetap menjadi faktor yang mendukung tenaga kerja patuh menggunakan APD. Patuh menggunakan APD berarti tenaga kerja berupaya memelihara kesehatannya dan melindungi diri dari bahaya keselamatan dan kesehatan kerja. Hasil penelitian ini juga sejalan dengan penelitian yang dilakukan oleh Kartika Dyah S.P dan Y. Denny A.W di unit produksi alumunium sulfat PT. Liku Telaga Gresik Tahun 2014 bahwa variabel pengetahuan berhubungan signifikan dengan kepatuhan menggunakan APD karena memiliki nilai signifikan $0,005<0,05$. Variabel pengetahuan memiliki kuat hubungan yang rendah yaitu nilai koefisien kontigensi 0,336 . Tenaga kerja yang tamat SMA akan lebih patuh untuk menggunakan APD dari pada yang tidak tamat SMA.

Tidak hanya itu, penelitian yang juga dilakukan oleh Humau (2012), menyatakan bahwa terdapat hubungan antara tingkat pendidikan tenaga kerja dengan kepatuhan menggunakan APD. Penelitian yang dikemukakan oleh Jannah (2009) juga mengemukakan hal yang sama tentang kuat hubungan pendidikan dengan kepatuhan menggunakan APD yang rendah. Rendahnya kuat hubungan pendidikan dengan kepatuhan menggunakan APD dikarenakan tingkat pendidikan tidak berpengaruh langsung terhadap penggunaan APD tetapi hanya mempengaruhi pola fikir tenaga kerja. Berdasarkan penelitian, pengetahuan termasuk dalam faktor predisposisi (Lawrence Green dalam Notoatmodjo, 2000) yaitu untuk dapat melakukan sesuatu (mengadopsi perilaku) seseorang 
harus tahu terlebih dahulu mengenai arti dan manfaatnya berprilaku tersebut dan pengaruh pengetahuan ini bisa mendorong terhadap suatu tindakan tergantung dari apa yang akan dilakukan nya pada saat bekerja. Pengetahuan juga merupakan faktor yang terpenting untuk terbentuknya perilaku seseorang, karena dari pengalaman dan penelitian terbukti bahwa perilaku yang didasari pengetahuan akan lebih langgeng dari perilaku yang tidak didasari oleh pengetahuan (Notoatmodjo, 2003).

Dengan meningkatnya pengetahuan responden diharapkan akan terjadi perubahan perilaku ke arah yang mendukung akan pentingnya kesadaran dalam mem proteksi diri sendiri dari bahaya paparan radiasi pada saat bekerja. Dalam hal ini secara keseluruhan responden memiliki pengetahuan yang baik tentang pengetahuan penggunaan pocket dosemeter personal radiasi walaupun ada beberapa responden tidak menerapkan perilaku bekerja aman dan ternyata tidak terjadi hal yang berakibat buruk terjadi padanya.

\section{Variabel Sikap}

Hasil distribusi responden berdasarkan variabel sikap pada penggunaan pocket dosemeter sebesar $54,5 \%$ mempunyai sikap kurang baik, sedangkan pengguna pocket dosemeter yang mempunyai sikap baik dan patuh sebanyak $81,2 \%$. Hal tersebut dapat dikatakan bahwa persentase petugas yang mempunyai sikap baik lebih patuh dibandingkan pada kelompok yang mempunyai sikap kurang baik. Hal ini sejalan dengan teori menurut Skiner (1938) dalam Wuryaningsih (2000), disebutkan bahwa sikap merupakan perilaku yang terselubung, artinya dengan sikap positif atau negatif belum tentu mempunyai kesadaran diri terhadap penggunaan APD seperti yang diharapkan dan perilaku ini merupakan bagian dari covert behavior yaitu pada tingkatan pengetahuan, kesadaran dan sikap. Hal ini juga dipertegas berdasarkan penelitian P Robin (2001), Sikap dapat berbentuk positif dan negatif, dalam sikap positif, kecenderungan tindakan adalah mendekati, menyenangi, mengharapkan objek tertentu, sedangkan sikap negatif terdapat kecenderungan untuk menjauhi, menghindari, membenci dan tidak menyukai objek tertentu.

Salah satu hal yang paling relevan tentang sikap adalah kenyataan bahwa seseorang cenderung mencari konsistensi. Ketidakselarasan tersebut terjadi ketika adanya ketidak konsistenan antara dua atau lebih sikap seseorang atau antara sikap dan perilaku seseorang. Teori ini juga menyatakan bahwa setiap individu berusaha untuk meminimalkan ketidakselarasan dan ketidak nyamananyang timbul akibat pemakaian film badge sebagai alat pemonitoring dosis radiasi personal. Tingkat pengaruh kepercayaan individu terhadap hal ini akan berdampak pada bagaimana reaksi mereka terhadap kondisi dimana mereka tidak memiliki pilihan, mereka tidak mungkin mau menerima perubahan sikap apabila ketidakselarasan itu muncul akibat dari instruksi atasan, tekanan untuk menurunkan ketidakselarasan akan lebih rendah jika perilaku tersebut dilakukan secara sukarela. Penghargaan (reward) juga mempengaruhi tingkat motivasi individu untuk meningkatkan kepatuhan seseorang. Tekanan yang timbul karena tingginya akan pentingnya kesadaran proteksi diri dapat dikurangi apabila disertai dengan penghargaan yang tinggi. Penghargaan berfungsi untuk meningkatkan personality (individu) seseorang.

\section{Variabel Ketersediaan alat}

Hasil distribusi responden berdasarkan variabel ketersediaan alat pada penggunaan pocket dosemeter sebesar 63,6\% menyatakan ketersediaan alat kurang baik, sedangkan pengguna pocket dosemeter yang menyatakan ketersediaan alat baik dan patuh sebanyak $83,3 \%$. Hal tersebut dapat dikatakan bahwa persentase petugas yang mempunyai ketersediaan alat baik lebih patuh dibandingkan pada kelompok yang menyatakan ketersediaan alat kurang baik. Hal ini sejalan dengan teori Notoatmodjo (2003) menyatakan bahwa ketersediaan alat merupakan salah satu faktor enabling yang mempengaruhi perilaku seseorang. Hasil penelitian Rengganis (2012) menyatakan 
bahwa tidak ada hubungan yang signifikan antara ketersediaan APD dengan kepatuhan menggunakan APD. Menurut pernyataan Azrul Azwar (1983) menyatakan bahwa tersedia atau tidaknya fasilitas yang dapat dimanfaatkan adalah hal lain yang penting dalam memunculkan perilaku.

Dalam hal ini responden sudah dapat menerapkan perilaku bekerja aman, patuh dan taat dalam penggunaan pocket dosemeter personal radiasi, walaupun masih terdapat petugas yang belum patuh dan taat pada penggunaan pocket dosemeter personal radiasi meskipun pada kenyataannya tidak terjadi hal yang berakibat buruk terjadi pada dirinya.

\section{Variabel Kenyamanan}

Hasil distribusi responden berdasarkan variabel kenyamanan pada penggunaan pocket dosemeter sebesar 58,3\% menyatakan alat yang dipakai kurang nyaman, sedangkan pengguna pocket dosemeter yang menyatakan alat yang digunakan nyaman dan patuh sebanyak $83,0 \%$. Hal tersebut dapat dikatakan bahwa persentase petugas yang merasa alat yang dipakai nyaman dan patuh lebih besar dibandingkan pada kelompok yang menyatakan alat yang dipakai kurang nyaman. Hal ini sejalan dengan teori Cushman dan Rosenberg (1991) menyatakan bahwa penggunaan alat keselamatan kerja memiliki pengaruh terhadap kenyamanan pekerja karena menghambat gerakan mereka, sehingga dalam bekerja menjadi lebih sulit dan adapula yang dapat mengganggu komunikasi. Meskipun demikian bukan menjadi pembenaran untuk tidak menggunakan alat pelindung diri saat bekerja, melainkan melakukan beberapa penyesuaian untuk dapat bekerja dengan maksimal dan memenuhi standar keselamatan (Inna Nesyi Barizqi, 2015).

Penelitian ini membuktikan penelitian yang dilakukan Cushman dan Rosenberg bahwa terdapat hubungan yang signifikan antara kenyamanan dengan kepatuhan penggunaan APD dengan nilai Chi-square sebesar19,212 ( $\mathrm{p}=0,000, \mathrm{p}<0,005)$. Hubungan kedua variabel bersifat lurus, artinya semakin nyaman menggunakan APD maka semakin patuh untuk menggunakan APD. Dalam hal ini dibuktikan dari hasil penelitian bahwa responden merasakan nyaman jika menggunakan pocket dosemeter personal radiasi pada saat bekerja, hal ini dikarenakan menurut responden penggunaan pocket dosemeter dirasakan jauh lebih baik jika dibandingkan dengan film badge masih mempunyai kelemahan dan kekurangan nya, diantara nya dikarenakan system pendeteksi hasil monitoring radiasi tidak bisa langsung dilihat atau dibaca tetapi masih harus dikirim ke Badan Pelayanan Fasilitas Kesehatan (BPFK) sedangkan pengiriman melalui jalur udara, kemungkinan masih terkena paparan radiasi sinar $\mathrm{x}$ yang berasal dari alat pendeteksi barang yang berada di bandara.

\section{Pelatihan}

Hasil distribusi responden berdasarkan variabel pelatihan pada penggunaan pocket dosemeter sebesar $40,0 \%$ menyatakan tidak adanya pelatihan, sedangkan pengguna pocket dosemeter yang menyatakan pelatihan baik dan patuh sebanyak $89,7 \%$. Hal tersebut dapat dikatakan bahwa persentase petugas yang mempunyai pelatihan baik dan patuh lebih besar dua kali dibandingkan pada kelompok yang menyatakan pelatihan tidak ada. Hal ini sejalan dengan teori Noe (2002) dalam Yuwono (2005) pelatihan adalah suatu kegiatan yang direncanakan oleh perusahaan untuk memfasilitasi proses belajar tenaga kerja agar dapat mencapai kompetensi dalam kepekerjaannya dalam menggunakan APD.

Menurut Mathis (2002), Pelatihan adalah suatu proses dimana orang-orang mencapai kemampuan tertentu untuk membantu mencapai tujuan organisasi. Pelatihan telah tertulis pada Undang-undan No.13 tahun 2003 tentang Ketenagakerjaan, Pasal 9 yang berbunyi “ Pelatihan kerja diselenggarakan dan diarahkan untuk membekali, meningkatkan, dan mengembangkan kompetensi 
kerja guna meningkatkan kemampuan, produktivitas, dan kesejahteraan." Hasil penelitian ini di dukung oleh penelitian yang dilakukan oleh Rengganis (2012) di unit produksi alumunium sulfat PT. Liku Telaga menyatakan bahwa pelatihan K3 mempunyai pengaruh yang signifikan terhadap penggunaan APD.

Menurut Bisen dan Priya (2010), pelatihan adalah suatu proses pembelajaran yang memperdalam pengetahuan, kemampuan, peraturan atau mengubah perilaku untuk meningkatkan prestasi kerja. Berdasarkan definisi pelatihan tersebut, maka perusa haan harus memberikan pelatihan tentang APD kemampuan cara menggunakan APD, peraturan yang mengatur tentang APD dan mengubah perilaku tidak patuh menjadi patuh menggunakan APD.

\section{Pengawasan}

Hasil distribusi responden berdasarkan variabel pengawasan pada penggunaan pocket dosemeter sebesar 52,6\% menyatakan tidak ada pengawasan, sedangkan pengguna pocket dosemeter yang menyatakan pengawasan baik dan patuh sebanyak $87,5 \%$. Hal tersebut dapat dikatakan bahwa persentase petugas yang mempunyai pengawasan baik dan patuh lebih besar dibandingkan pada kelompok yang menyatakan tidak ada pengawasan. Hal ini sejalan dengan pengawasan yang dilaksanakan oleh petugas K3 sesuai dengan undang-undang No.1 tahun 1970 tentang keselamatan kerja, Pasal 5 ayat (1) yang berbunyi " Direktur melakukan pelaksanaan umum terhadap undnagundang ini, sedangkan para pegawai pengawas dan ahli keselamatan kerja ditugaskan menjalankan pengawasan langsung terhadap ditaatinya undang-undang ini dan membantu pelaksanaannya.

Berdasarkan hasil penelitian, 10 orang pekerja kerangka bangunan menyatakan ada sanksi dari petugas K3. Sanksi dari petugas K3 berupa pemberian denda kepada mandor dan pekerja. Penggadaan sanksi disiplin kerja bagi tenaga kerja yang melanggar norma-norma perusahan, bertujuan untuk memperbaiki dan mendidik para tenaga kerja yang melakukan pelanggaran disiplin (Sastrohadiwiryo, 2005). Dalam menetapkan jenis sanksi disiplin yang akan dijatuhkan kepada tenaga kerja yang melanggar, hendaknya dipertimbangkan dengan cermat, teliti, dan seksama bahwa sanksi disiplin yang akan dijatuhkan setimpal dengan tindakan dan perilaku yang diperbuat. Dengan demikian, sanksi disiplin tersebut dapat diterima oleh rasa keadilan (Sastrohadiwiryo, 2005).

Dalam hal ini dibuktikan oleh hasil penelitian dilapangan responden menyatakan adanya pengawasan baik berupa inspeksi maupun penegakan hukum serta sanksi terhadap penggunaan fasilitas radiasi dan zat radioaktif serta sudah diberlakukannya sanksi yang diberikan jika diketahui ada pekerja radiasi yang tidak patuh pada penggunakan pocket dosemeter personal radiasi pada saat bekerja yang bertujuan untuk memastikan keselamatan dan keamanan dalam pemanfaatan tenaga nuklir dibidang fasilitas radiasi dan zat radioaktif. Hal ini dibuktikan dari hasil penelitian terdapat kesesuaian izin operasional alat, ketersediaan petugas PPR, adanya monitoring pemantauan dosis radiasi, penyelenggaraan pemeriksaan kesehatan petugas radiasi, ketersediaan standar operasional prosedur, dan ketersediaan peralatan keselamatan radiasi yang memadai di lingkungan kerja.

Hal ini sejalan dengan laporan tahunan Bappeten tahun 2014 yang berbunyi tentang kegiatan inspeksi merupakan salah satu tugas pokok Bappeten sebagai badan pengawas, yang bertujuan untuk memastikan keselamatan dan keamanan dalam FRZR dan tercapainya kondisi keselamatan dan keamanan dalam pemanfaatan tenaga nuklir terindikasi pada 7 (tujuh) parameter yaitu, adanya kesesuaian kondisi izin, ketersediaan SDM berkompeten (PPR), Pelaksanaan pemantauan dosis radiasi, penyelenggaraan pemeriksaan kesehatan pekerja radiasi, ketersediaan dokumen rekaman keselamatan dan keamanan, dan ketersediaan peralatan keselamatan radiasi yang memadai. 


\section{KESIMPULAN}

Dari hasil penelitian secara keseluruhan diketahui sebagai berikut: Pengguna pocket dosemeter berpengetahuan tidak baik dan tidak patuh sebesar $60 \%$, sedangkan pengguna pocket dosemeter berpengetahuan baik dan patuh sebesar $81,6 \%$. Pengguna pocket dosemeter sebesar $54,5 \%$ mempunyai sikap kurang baik, sedangkan pengguna pocket dosemeter yang mempunyai sikap baik dan patuh sebanyak $81,2 \%$. Pengguna pocket dosemeter sebesar 63,6\% menyatakan ketersediaan alat kurang baik, sedangkan pengguna pocket dosemeter yang menyatakan ketersediaan alat baik dan patuh sebanyak $83,3 \%$. Pengguna pocket dosemete $r$ sebesar $58,3 \%$ menyatakan alat yang dipakai kurang nyaman, sedangkan pengguna pocket dosemeter yang menyatakan alat yang digunakan nyaman dan patuh sebanyak $83,0 \%$. Pengguna pocket dosemeter sebesar $40,0 \%$ menyatakan tidak adanya pelatihan, sedangkan pengguna pocket dosemeter yang menyatakan pelatihan baik dan patuh sebanyak $89,7 \%$. Pengguna pocket dosemeter sebesar 52,6\% menyatakan tidak ada pengawasan, sedangkan pengguna pocket dosemeter yang menyatakan pengawasan baik dan patuh sebanyak $87,5 \%$.

\section{DAFTAR PUSTAKA}

Abidin Zaenal dkk, 2008 Hubungan Perilaku Keselamatan dan Kesehatan Kerja, Jurnal Sekolah Tinggi Teknologi Nuklir, Batan

Akhadi Muklisin, (2000), Proteksi Radiasi : Ketentuan Keselamatan Kerja Terhadap Diri Sendiri, jakarta, BATAN

Atomic Energy Control Bourd, Bureau of medical devices, Department Healt and Welfare, “ Training manual " Canada (1993)

Ballinger, Philip W, (1995) Radiograpich Position and Radiologic Procedures, Seven Edition, Mosby:London.

BAPETEN, (2003), Himpunan Peraturan Peraturan Perundang-undangan Ketenaganukliran, Penerbit Badan Pengawas Tenaga Nuklir, Jakarta

Cember, H, (1992), Introduction to health physics, Second edition, Revised and Enlarged, Mc Grawhild, inc,New York, USA.

Departement Healt and welfare, "X-ray equipment in medical diagnosis part A : Recommended Safety Procedures For Instaltion and use ', Safety Last modifield (2002), Canada

Green, L. W, Kreuter (2000), Healt Promotion Planning, An Educational and Envirotmental Approach, $2^{\text {nd }}$ Edition, May Field Publishing Company, California.

Hastono, Sutanto Priyo, (2006), Statistik Kesehatan, Jakarta : PT. Raja Grafindo Persada.

Hadi Sutrisno dan Parmadiningsih Y, (2000), Seri Program Statistik Versi 2000, Universitas Gadjah Mada, Yogyakarta.

Himpunan Peraturan Perundang-undangan Ketenaganukliran, BAPETEN : Jakarta.

IAEA, (1999), Safety Series International Basic Safety standards for protection against Ionizing Radiation and For the safety of radition sources, international Atomic Energy Agency, Vienna.

ICRP, (1990), Proteksi Radiasi Pekerja Radiasi, Badan Tenaga Nuklir Nasional.

Iman Khasani, Soemanto, (1990), Keselamatan Kerja dalam Laboratorium Kimia, Jakarta : PT. Gramedia

International A. Tomic Energy Agency, International Basic Safety Standards For Protection Against Ionizing Radiation and For The Safety Of Radiation Sources "IAEA Safety, Vienna, (1996).

IRCP, (1991), “ International Commisision on Radiological Protection. Recommendations Report No. 60", Pergarnon, New York.

Kunto Wiharto, (1992), “ Pengantar Keselamatan Kerja, Diklat Keselamatan dan Kesehatan Kerja”, Pusat Pendidikan dan Pelatihan Badan Tenaga Nuklir Nasional, Jakarta. 
Laporan keselamatan Nuklir, (2009) Nuclear energy regulatory agency, Badan Pengawas Tenaga Nuklir.

Laporan keselamatan Nuklir, (2014) Nuclear energy regulatory agency, Badan Pengawas Tenaga Nuklir.

Notoatmodjo, Soekidjo, (2010), Metodologi Penelitian kesehatan, Jakarta : PT. Rineka Cipta

Notoatmodjo, Soekidjo, (2014), Ilmu Perilaku Kesehatan, Jakarta : PT. Rineka Cipta

Peraturan Pemerintah RI No.63, (2000), Keselamatan dan Kesehatan terhadap Pemanfaatan Radiasi Pengion.

Purwaningtyas, (2000), Evaluasi Penerimaan Dosis Paparan Radiasi Pekerja, dibidang Akselator, Pusat penelitian dan Pengembangan Teknologi Maju, Badan Tenaga Nuklir Nasional, Yogyakarta.

Setiawati, L. (1996), “ Keselamatan Kerja dan Pencegahan Kecelakaan Kerja “, Pelatihan Keahlian Hiperkes dan Keselamatan Kerja Bagi Guru-guru SMK DIY.

Suatmadji, A, (1993), Efek Radiasi terhadap Materi Biologi, Pelatihan Proteksi Radiasi, Pusat pendidikan dan Pelatihan, Badan Tenaga Nuklir, Yogyakarta.

Widyati S, Lubis W, Tedjasari RS, Yatim S, (1997), "Evaluasi Keselamatan Pekerja di PPTA Serpong”. Jurnal Keselamatan Radiasi dan Lingkungan, ISSN : 0854-4085, Jakarta

Wiryosimin S, (1995), Mengenal Azas Proteksi Radiasi, Penerbit FMIPA Institut Teknologi Bandung 